\title{
Pharmacovigilance in Cabo Verde: Measuring the Awareness and Knowledge of Consumers
}

\section{Carla Djamila Reis ${ }^{*}$, Calida Etzana Veiga and Jailson Jesus Martins}

Agência de Supervisão e Supervisão de Produtos Farmacêuticos e Alimentares (ARFA), Praia, Cape Verde

*Corresponding author: Carla Djamila Reis, Master in Pharmaceutical Regulation, Agência de Regulação e Supervisão de Produtos Farmacêuticos e Alimentares (ARFA), Praia, Cape Verde, Tel: 23826264 10; E-mail: djamila.reis@arfa.gov.cv

Received date: February 22, 2016; Accepted date: March 01, 2016; Published date: March 07, 2016

Copyright: (C) 2016 Reis CD, et al. This is an open-access article distributed under the terms of the Creative Commons Attribution License, which permits unrestricted use, distribution, and reproduction in any medium, provided the original author and source are credited.

\begin{abstract}
Background: Rational use of medicine involves everyone but half of all medicines globally are used irrationally. Therefore, the patient knowledge about risk and benefit of medicines can be crucial to maximize the benefit of medicine and limit severe consequences such, adverse drug reaction, drug resistance and even death.
\end{abstract}

Purpose: To describe the knowledge and attitudes of the consumers regarding the rational use of medicine.

Methods: A descriptive study was performed for consumers' knowledge and attitudes regarding rational use of medicine. The questionnaire was applied during 1 week (from 18 to 26 August 2015) in all urban areas of the capital of Cabo Verde to a sample of 75.257 individual. The data were analyzed using descriptive statistics and chi-square $\left(x^{2}\right)$ tests.

Results: In general, $87.3 \%$ of the respondents recognized the benefit of medicines. However $29.3 \%$ of the respondents were not aware that the use of medicines involves a risk. The quality of generic medicine was also not clear for $78.3 \%$ of the respondents. In relation to pharmacovigilance, $67.5 \%$ of the respondents were aware of adverse drug reactions (ADR) and $35.2 \%$ knew that they can report an ADR.

Conclusion: Awareness campaigns are needed for broader consumer information and to promote patient safety and rational use of medicines.

Keywords: Cabo Verde; Consumers; Knowledge; Attitudes; Medicine; Rational use; Pharmacovigilance; Adverse drug reactions; Patient safety

\section{Background}

The amplified access to therapeutic innovation has not always been supported by systems to set up measures to monitor and ensure patient safety. The thalidomide tragedy served as a wake-up call to the fact that the use of any drug represents a risk and the benefit / risk ratio may changes during the post-marketing phase. Since then, different methodologies are used to collect quality, efficacy and safety information of medicines. The existing system of adverse drug reactions (ADR) monitoring has been essentially based on the spontaneous reporting of healthcare professionals as a mean source of information [1]. However, the involvement of patient is becoming increasingly an important issue in pharmacovigilance.

The number of countries who encourage consumers to report ADRs is now increasing and a guideline has been developed for setting up patient reporting systems. The experiences coming out from patients report showed that the patient reporting can be a good source of information for drug safety monitoring both in terms of qualitative and quantitative value according to the 3 years-experience obtained in Netherlands [2,3]. In the United Kingdom, the evaluation of the first 6 months of patient reporting showed that there were no differences in the proportion of serious ADRs reported, as compared to the reports made by health professionals [4].

In Portugal a study reveal that consumers are more likely to do spontaneous report about severe reactions or if they are worried about the symptoms [5]. Moreover, the quality of patient reports appears so far to be similar to the healthcare professional (HCP) reports and studies have shown the possible benefits of patient reporting for signal detection [2]. In fact, since rational use of medicine touches everyone and half of all medicines globally are used irrationally [6], the patient knowledge about risk and benefit of medicines can be crucial to maximize the benefit of medicine and limit severe consequences such, $\mathrm{ADR}$, drug resistance and even death.

In Cape Verde, despite the remarkable progress in overall health indicators, a recent study showed that one in four Cabo Verde inhabitants $(25.6 \%)$ purchase medicines on illegal market and that they are not aware of the risks of purchasing medicine on illegal market [7]. Therefore, the need for better involvement of consumers in their healthcare implies that they are or can be sufficiently well informed.

The objective of this survey was to characterize the knowledge and attitudes of consumers regarding the rational use of medicine to gain insight into what they know about medicine in order to engage them to participate in the pharmacovigilance system in Cabo Verde. 


\section{Methods}

The survey was conducted with the distribution of a questionnaire where the consumers were asked about benefit and risk of medicines and opinions about reporting ADRs. A multidisciplinary team with pharmaceutical, biomedical and statistical background, working at Food and Drug Regulatory Agency (Agência de Regulação e Supervisão dos Produtos Farmacêuticos e Alimentares - ARFA), drew the questionnaire then discussed and validated by the official body in Cabo Verde, the National Institute of Statistics.

The questionnaire was field tested by several volunteer consumers $(\mathrm{n}=30)$, not included in the sample, in order to improve the understanding of the question. The final questionnaire was two pages long and divided into the following sections: (1) respondents' characteristics (age, sex, marital status, school level, income and working status) and (2) questions related to knowledge about rational use of medicine and reporting attitudes.

The questionnaire were applied during 1 week (from 18 to 26 August 2015) in all urban areas of the capital of Cabo Verde (Praia) which is the largest population center of the country (28\% of the total weight of the Cape Verdean population). The target population included individuals resident in Praia aged greater than or equal to 18 years. A total of 75.257 individuals answered the survey during the 1 week period.

The questionnaire was anonymous, and the data were intended only for scientific purposes of this study and were stored in agreement with confidentiality regulations. For the descriptive analysis of results, association chi-square tests were performed with $95 \%$ confidence level that allow to check the independence between two indicators studied and to measure the intensity of the association.

The database and analysis was done using Statistical Package for Social Sciences, version 20.0 (SPSS Inc.). Results are presented with numbers, percentages and graphs for categorical variables.

\section{Results}

The characterization of the population that responded to the questionnaire in terms of age indicates that $33.3 \%$ of those surveyed were between 25 to 37 years old. The mean age was 37.8 years and there were more female respondents (51.2\%). About $44.1 \%$ of respondents have a corresponding level of education to the High school.

In terms of economic characterization, about $47.6 \%$ of the respondents work and $25 \%$ of respondents are unemployed. With regard to the income, $23.7 \%$ of those interviewed has a household income between 90 to 272 Euros, followed by $15.1 \%$ with an income less than 90 Euros.

In general, $87.3 \%$ of the respondents recognized the benefit of using medicines. However, $29.3 \%$ of the respondents were not aware that the use of medicines involves a risk. The quality of generic medicine was also not clear for $78.3 \%$ of the respondents. The perception that food or medicinal herbal can interact with medicine was not clear among $34 \%$ of the respondents. The Table 1 shows the knowledge of patients about the self-medication and treatment compliance.

\begin{tabular}{|c|c|c|c|}
\hline & True & False & NS / NR \\
\hline KNOWLEDGE OF CONSUMERS REGARDING THE RATIONAL USE OF MEDICINE & Row N \% & Row N \% & Row N \% \\
\hline Medicines used to treat and cure diseases & $87,3 \%$ & $9,2 \%$ & $3,5 \%$ \\
\hline All medicines are $100 \%$ safe & $29,3 \%$ & $63,5 \%$ & $7,2 \%$ \\
\hline Use medicines correctly, allows you to increase the benefits and limit the risks & $93,1 \%$ & $3,9 \%$ & $3,1 \%$ \\
\hline Visit a physician before taking a medicine is a responsible way to take care of your health & $97,0 \%$ & $2,3 \%$ & $0,6 \%$ \\
\hline $\begin{array}{l}\text { Follow the indications, amount and duration of treatment recommended by your physician is a } \\
\text { correct way to use the medicine }\end{array}$ & $97,6 \%$ & $1,7 \%$ & $0,7 \%$ \\
\hline A medicine prescribed for you is always appropriate for another person & $8,6 \%$ & $88,0 \%$ & $3,4 \%$ \\
\hline Medicines purchased outside pharmacies may be fake or of low quality. & $81,0 \%$ & $13,1 \%$ & $5,9 \%$ \\
\hline In Cape Verde, the sale of medicines outside pharmacies is prohibited by law & $75,6 \%$ & $11,4 \%$ & $13,0 \%$ \\
\hline $\begin{array}{l}\text { Before being marketed every medicine must demonstrate that it is efficacious, safe and with } \\
\text { quality. }\end{array}$ & $89,0 \%$ & $3,0 \%$ & $8,1 \%$ \\
\hline Generics medicines provide the same guarantee for my health as branded medicines & $21,7 \%$ & $15,4 \%$ & $62,9 \%$ \\
\hline Places exposed to light, heat and / or moisture are the best places to keep medicines & $8,6 \%$ & $85,8 \%$ & $5,5 \%$ \\
\hline $\begin{array}{l}\text { Check expiry date and the packaging condition of medicine before buying is important to ensure a } \\
\text { safer use. }\end{array}$ & $95,9 \%$ & $2,8 \%$ & $1,2 \%$ \\
\hline An adverse reaction is a symptom or side effect caused by a medicament. & $67,5 \%$ & $9,5 \%$ & $23,0 \%$ \\
\hline The reporting of adverse reactions helps to ensure that medicines are safer in Cape Verde & $75,1 \%$ & $5,3 \%$ & $19,6 \%$ \\
\hline
\end{tabular}

Table 1: Knowledge of consumers regarding the rational use of medicine. 
In relation to the national pharmacovigilance system, for $67.5 \%$ of the respondents the concept of adverse drug reaction (ADR) was clear and $35.2 \%$ knew that they can report an ADR.

In terms of attitudes, the results shows that consumer tend to reuse medicine they have in house for symptoms apparently "simple" such headache and to inform the healthcare professional if they suspect of an ADR. The Table 2 characterize the attitude of consumers.

\begin{tabular}{|c|c|c|c|}
\hline & Agree & Disagree & NS / NR \\
\hline ATTITUDES OF CONSUMERS REGARDING THE RATIONAL USE OF MEDICINE & Row N \% & Row N \% & Row N \% \\
\hline Recommend to a sick neighbour / relative / friend to seek medical advice is a useful and responsible way to help him & $98,6 \%$ & $1,0 \%$ &, $4 \%$ \\
\hline A medicine recommended by a neighbour / relative / friend is right for you & $12,9 \%$ & $85,0 \%$ & $2,1 \%$ \\
\hline Medical advice is essential to establish a correct diagnosis and buy the right medicine to his illness. & $96,7 \%$ & $2,6 \%$ &, $7 \%$ \\
\hline Buy medicine outside pharmacies jeopardizes your life and that of your family & $93,4 \%$ & $5,3 \%$ & $1,3 \%$ \\
\hline $\begin{array}{l}\text { You would choose to buy a medicine at the grocery store even if you had the possibility to buy medicines per unit and at } \\
\text { a cheaper price at the pharmacy }\end{array}$ & $10,2 \%$ & $82,6 \%$ & $7,2 \%$ \\
\hline
\end{tabular}

Table 2: Attitudes of consumers regarding the rational use of medicine.

\section{Discussion}

This first study aims to describe the knowledge and attitudes of the consumers regarding the rational use of medicine.

In terms of knowledge about medicines, the study reveals two important findings: one is that there is some mistrust regarding the quality of generics and the other is the lack of perception that medicine involves a risk.

Therefore, considering that the use of generic medicine is often encouraged as a cost-containment measure, especially in a resourcelimited country such Cabo Verde, the improvement of confidence in generic medicine reveals paramount. The sceptic attitude regarding generic medicine was also confirmed among the respondents when questioned if they used to ask for a generic medicine in pharmacy instead of brand mark. The result is in line with systematic review, which suggests that opinions regarding generics have improved but some mistrust remain [8]. Moreover, the studies also suggest that as patient trust in their physician often overrules their personal mistrust of generic medicines so, enhancing the opinions of physicians regarding generics may have particular importance in strategies to promote usage and acceptance of generic medicines [8].

For better understanding of this opinion regarding generics, chisquare tests were used to identify dependent relationship with education, income and area of residence. There was relation identified with education $(\mathrm{p}=0.00)$ and income $(\mathrm{p}=0.00)$ and area of residence $(p=0.000)$. The lower level of education and income seems to affect the opinions that generic medicines do not have quality, which is in line with other studies [8].

Regarding medicine-risk perception and reporting attitudes, the results confirm the findings of other studies in which most participants did not expect to experience ADR during the use of medicines. The respondents identified correctly the concept of ADR but they do not understand that the use of medicine involves the risk of ADR. The misconception of medicine-risk may have important impact on the reporting system because if consumers do not suspect that a medicine may be the responsible for an ADR, they would never report to the physician or to the pharmacovigilance center, despite the willingness to do so.

\section{Conclusion}

This survey suggests the need for broader patient information and education on the benefits and risks of using medicines to modify perceptions and mistrust, especially about generic medicine. So, mass campaign such TV and radio program for public information should be considered as instruments to promote patient safety and rational use of medicines.

\section{References}

1. Goldman SA (1998) Limitations and strengths of spontaneous reports data. Clin Ther 20 Suppl C: C40-44.

2. van Grootheest K, de Jong-van den Berg L (2004) Patients' role in reporting adverse drug reactions. Expert Opin Drug Saf 3: 363-368.

3. de Langen J, van Hunsel F, Passier A, de Jong-van den Berg L, van Grootheest K (2008) Adverse drug reaction reporting by patients in the Netherlands: three years of experience. Drug Saf 31: 515-524.

4. Blenkinsopp A, Wilkie P, Wang M, Routledge PA (2007) Patient reporting of suspected adverse drug reactions: a review of published literature and international experience. Br J Clin Pharmacol 63: 148-156.

5. Matos C, van Hunsel F, Joaquim J (2015) Are consumers ready to take part in the Pharmacovigilance System?--a Portuguese preliminary study concerning ADR reporting. Eur J Clin Pharmacol 71: 883-890.

6. (2004) Promoting rational use of medicines saves lives and money, WHO experts say. Saudi Med J 25: 1309-1310.

7. Reis CD, Tavares EJ, Martins JJ (2015) Illegal Market of Medicines in Cabo Verde: Characterization for Action. J Pharmacovigil 3: 1-5.

8. Dunne SS, Dunne CP (2015) What do people really think of generic medicines? A systematic review and critical appraisal of literature on stakeholder perceptions of generic drugs. BMC Med 13: 173. 